\title{
Erratum zu: Produktionsmanagement
}

\section{Günther Schuh und Carsten Schmidt (Hrsg.)}

Erratum zu: G. Schuh et al., Eigenfertigungsplanung und -steuerung, DOI 10.1007/978-3-642-54288-6_5

In Kapitel 5 auf Siete 208 wurde das Wort „dynamischen” falsch erfasst und durch ,statischen” ersetzt. Es wurde jetzt korrigiert.

$\overline{\text { Die aktualisierte Online-Version }}$ des Originalkapitels finden Sie unter https://doi.org/10.1007/978-3-642-54288-6_5.

(C) Springer-Verlag Berlin Heidelberg, 2014, korrigierte publikation 2021

G. Schuh et. al (Hrsg.), Produktionsmanagement, 